\section{Gategory}

Synthesis of

Heterocycles

\section{Key words}

azabicyclo[2.2.2]octanes

malononitriles

dibenzalacetones

A. ALIZADEH, * V. SADEGHI, F. BAYAT, L.-G. ZHU (TARBIAT MODARES UNIVERSITY, TEHRAN, IRAN AND ZHEJIANG UNIVERSITY, HANGZHOU, P. R. OF CHINA)

Highly Efficient Diastereoselective Synthesis of Azabicyclo[2.2.2]octanes

Synlett 2014, 25, 2609-2612.

\title{
One-Pot Diastereoselective Synthesis of Azabicyclo[2.2.2]octanes
}

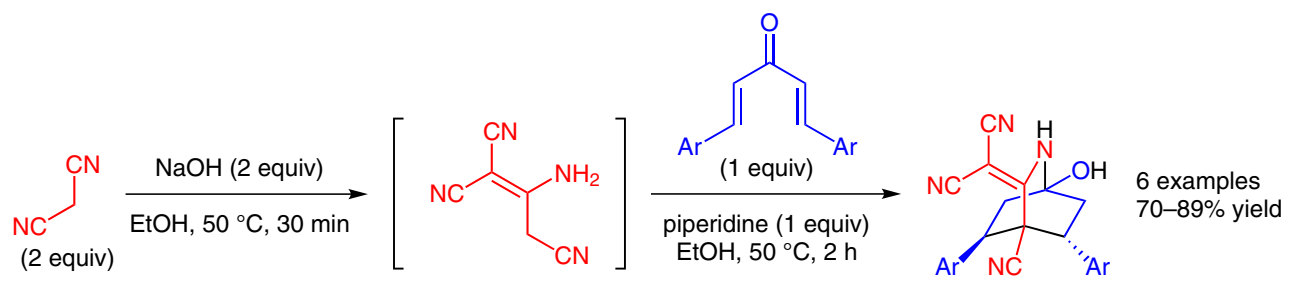

$\mathrm{Ar}=\mathrm{Ph}, 3-\mathrm{BrC}_{6} \mathrm{H}_{4}, 3-\mathrm{O}_{2} \mathrm{NC}_{6} \mathrm{H}_{4}, 4-\mathrm{MeOC}_{6} \mathrm{H}_{4}, 4-\mathrm{ClC}_{6} \mathrm{H}_{4}, 3,4-\mathrm{Me}_{2} \mathrm{OC}_{6} \mathrm{H}_{3}$

Significance: Reported is the base-mediated synthesis of azabicyclo[2.2.2]octanes through the reaction of dibenzalacetone and malononitrile. The products were unambiguously identified using NMR and IR spectroscopy as well as mass spectrometry and, for one example, by $\mathrm{X}$-ray diffraction analysis. The starting benzalacetones are easily synthesized from benzaldehyde and acetone (C. R. Conard, M. A. Dolliver Org. Syn. 1932, 12, 22). The method was optimized with respect to solvent, temperature and base, and the substrate scope was modestly examined using electron-rich and electron-poor aromatic substitution. The electronics of the ring had surprisingly little effect on the yield of the reaction; however, ortho-substituted dibenzalacetones did not provide products, probably due to steric hindrance effects. Also unsuccessful were dibenzalacetones with para-hydroxyaryl substituents, possibly due to strong electrondonating effects.
Comment: General interest in the azabicyclo[2.2.2] octane (isoquinuclidine) structure is fueled by its presence in many interesting natural products, and also its wide array of both pharmaceutical and synthetic uses. Interestingly, the cinchona alkaloids contain quinuclidine part structures and have many pharmacological properties, such as muscle relaxant, analgesic, and antimalarial. They are also very useful as organocatalysts (see Book below). Of the several methods for the synthesis of azabicyclo[2.2.2]octanes outlined in the introduction to this new work, many suffer from substrate scope issues or poor endo/exo selectivity. The current method should prove useful as it uses easily accessible or readily available starting materials to diastereoselectively provide moderate to good yields of new compounds in an efficient, operationally simple one-pot process.

Book: C. E. Song An Overview of Cinchona Alkaloids in Chemistry, In Cinchona Alkaloids in Synthesis and Catalysis: Ligands, Immobilization and Organocatalysis, C. E. Song, Ed.; Wiley-VCH: Weinheim, Germany, 2009, 1-10. 